meticulous harvest of the BITA conduits to the appropriate length and quality, ${ }^{6}$ the use of arterial conduits in various configurations without limiting yourself only to the in situ grafting configuration, capability of performing both offpump and on-pump CABG at the same proficiency level when required, all those including others, are not just "recommendations" any more but incumbent prerequisites upon a coronary surgeon.

Finally, the openly well-discussed flaws in the ART as well as the recent striking discoveries with the controversial EXCEL (Evaluation of the Xience Everolimus-Eluting Stent vs Coronary Artery Bypass Surgery for Effectiveness of Left Main Revascularization) ${ }^{7}$ trial opened a narrow loophole reflecting somewhat on the quality and fragility of scientific randomized clinical trials. Physicians should have the integrity to explore flaws in their clinical conduct as well as in their clinical research, so patients could rely upon their actual surgical capabilities, unbiased clinical judgment, and on authoritative medical guidelines based on accurate and well-designed research, as perfectly recently stated: "We're not talking about 2 tablets for a headache. We're talking about people dying." "

\section{References}

1. Taggart DP, Gaudino MF, Gerry S, Gray A, Lees B, Sajja LR, et al. Ten-year outcomes after off-pump versus on-pump coronary artery bypass grafting: insights from the Arterial Revascularization Trial. J Thorac Cardiovasc Surg. 2021;162: 591-9.e8.

2. Taggart DP, Benedetto U, Gerry S, Altman DG, Gray AM, Lees B, et al. Bilatera versus single internal-thoracic-artery grafts at 10 years. N Engl J Med. 2019;180: 437-46.

3. Shroyer AL, Hattler B, Wagner TH, Collins JF, Baltz JH, Quin JA, et al. Five year outcomes after on-pump and off-pump coronary-artery bypass. N Engl J Med. 2017;377:623-32.

4. Lamy A, Deveraux PJ, Prabhakaran D, Taggart DP, Hu S, Paolasso E, et al. Effects of off-pump and on-pump coronary-artery bypass grafting at 1 year. $N$ Engl J Med. 2013;368:1179-88.

5. Diegler A, Borgermann J, Breuer M, Boning A, Ursulescu A, Rastan A, et al. Offpump versus on-pump coronary-artery bypass grafting in elderly patients. $N$ Engl J Med. 2013;368:1189-98

6. Benedetto U, Altman DG, Gray AM, Gerry S, Gray A, Lees B, et al. Pedicled and skeletonized single and bilateral internal thoracic artery grafts and the incidence of sternal wound complications: insights from the arterial revascularization trial. $J$ Thorac Cardiovasc Surg. 2016;152:270-6.

7. Stone GW, Kappetein P, Sabik JF, Pocock SJ, Morice MC, Puskas J, et al; for the EXCEL Trial Investigators. Five year outcomes after PCI or CABG for left main coronary disease. N Engl J Med. 2019;381:1820-30.

8. O'Riordan M. Former EXCEL Investigator alleges trial manipulation, prompting vehement denials. TCTMD News Interventional; 2019. Available at: https://www. tctmd.com/news/former-excel-investigator-alleges-trial-manipulationprompting-vehement-denials. Accessed February 26, 2020.

\title{
Commentary: Off-pump coronary arterial bypass grafting, a demanding instrument only for
} a master?

\section{Sung Jun Park, MD, and Joon Bum Kim, MD, PhD}

On-pump conventional coronary arterial bypass grafting (CABG) surgery has been a gold standard for surgical

\footnotetext{
From the Department of Thoracic and Cardiovascular Surgery, Asan Medical Center, University of Ulsan College of Medicine, Seoul, South Korea.

Disclosures: Authors have nothing to disclose with regard to commercial support.

Received for publication March 25, 2020; revisions received March 25, 2020; accepted for publication March 26, 2020; available ahead of print April 5, 2020. Address for reprints: Joon Bum Kim, MD, PhD, Department of Thoracic and Cardiovascular Surgery, Asan Medical Center, University of Ulsan College of Medicine, 88, Olympic-Ro-43-Gil, Songpa-Gu, Seoul, Korea 05505 (E-mail: jbkim1975@ amc.seoul.kr).

J Thorac Cardiovasc Surg 2021;162:603-4

$0022-5223 / \$ 36.00$

Copyright (c) 2020 by The American Association for Thoracic Surgery

http://dx.doi.org/10.1016/j.jtcvs.2020.03.069
}

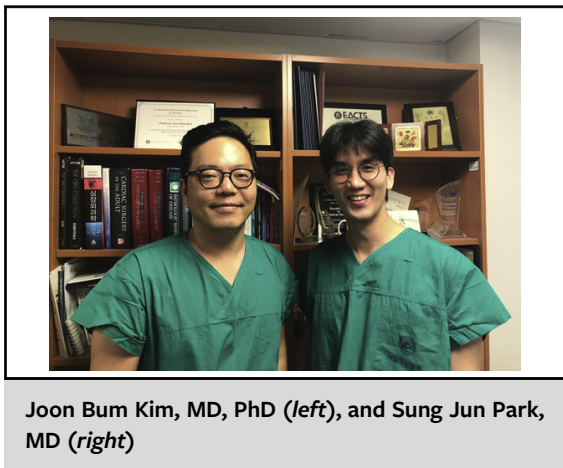

CENTRAL MESSAGE

As off-pump CABG seems to obtain comparable long-term outcomes with on-pump surgery only when performed by experts, structured training platforms need to be developed and organized. 
coronary revascularization, whereas off-pump CABG also has gained widespread acceptance and entered into the mainstream of clinical practice with improvements in surgical devices and techniques. ${ }^{1}$ Off-pump CABG primarily intends to enhance overall outcomes by avoiding perioperative complications associated with the use of cardiopulmonary bypass; however, long-term outcomes have been questioned due to concerns regarding potential incomplete revascularization and more frequent graft failure. ${ }^{2,3}$ Until now, the procedural validity of off-pump CABG compared with on-pump surgery has remained one of the most controversial issues in cardiac surgery. Recent largescale randomized clinical trials on this issue have revealed conflicting results, ${ }^{4-6}$ which was explained mainly by differing operating surgeon's expertise in off-pump approach. As off-pump CABG is technically more demanding, its outcomes are more likely to depend on the experience of the surgeon. In the current issue of the Journal, Taggart and colleagues ${ }^{7}$ reconfirmed the importance of surgeon's experience in off-pump CABG using the renowned Arterial Revascularization Trial (ART) data.

This post-hoc analysis of the ART trial involved $2951 \mathrm{pa}-$ tients who received CABG either off-pump (1252) or onpump (1699), and 10-year outcomes, including all-cause mortality and a composite of outcomes of death, myocardial infarction, stroke, and repeat revascularization, were compared in the 1078 pairs of a propensity-matched cohort. ${ }^{7}$ The study concluded that, when performed by experienced-hands, off-pump CABG showed comparable long-term outcomes over 10 years with those of on-pump surgery. Moreover, the authors further emphasized that the comparable outcomes were not influenced by the use of single versus bilateral internal thoracic artery.

In the ART trial, ${ }^{8}$ the level of experience in off-pump surgeries of the original cohort appeared to be substantially high, which is somewhat reflected by the following features: (1) comparable number of grafts in off- versus on-pump surgeries ( 3.20 vs $3.19 ; P=.70)$, (2) exceptionally low conversion rate $(2.5 \%)$ from off- to on-pump surgery, and (3) significantly frequent use of bilateral internal thoracic arteries in off-pump CABG versus on-pump CABG $(47.4 \%$ vs $40.7 \% ; P<.001)$. Furthermore, 1075 off-pump procedures performed only by 21 surgeons (average $>50 /$ surgeon) also represent a high level of expertise in off-pump surgeons. Of note, even performed by experienced hands, however, off-pump CABG failed to acquire superior outcomes compared with on-pump surgery. Furthermore, in the subset of cases performed by low-volume surgeons, off-pump surgery was associated with significantly greater risks of cardiovascular death (hazard ratio, 2.39; 95\% confidence interval, 1.28-4.47; $P=.006$ ) and late stroke (hazard ratio, $3.97 ; 95 \%$ confidence interval, 1.81-7.95; $P<.001$ ) when compared with on-pump CABG. In available randomized clinical trials or large-scale registry-type series to date, there have been no convincing evidence that off-pump CABG has superior long-term outcomes than conventional on-pump CABG, which was confirmed by the present posthoc analysis once again. ${ }^{4-6,9}$

It is true that off-pump CABG is a valuable strategy in certain conditions, such as cases with porcelain/heavily atherosclerotic ascending aorta. Furthermore, patients with severely reduced ejection fraction or chronic kidney disease may be benefit from an off-pump strategy by reducing perioperative risks associated with cardiopulmonary bypass use. ${ }^{10}$ As the volume of CABG surgery has continuously declined worldwide, however, mastering the off-pump technique is getting more and more difficult than ever. To acquire desirable results with off-pump CABG, the authors also emphasized in the manuscript that off-pump CABG may need to be recognized as a discrete subspecialty; in addition, a formally structured training platform may offer opportunities for lessexperienced surgeons to overcome technical challenges and subsequently to pass beyond the learning curve.

\section{References}

1. Sellke FW, Del Nido PJ, Swanson SJ. Sabiston \& Spencer Surgery of the Chest. 9th ed. Philadelphia, PA: Elsevier; 2016.

2. Kim JB, Yun SC, Lim JW, Hwang SK, Jung SH, Song H, et al. Long-term survival following coronary artery bypass grafting: off-pump versus on-pump strategies. J Am Coll Cardiol. 2014;63:2280-8.

3. Takagi H, Matsui M, Umemoto T. Off-pump coronary artery bypass may increase late mortality: a meta-analysis of randomized trials. Ann Thorac Surg. 2010;89: $1881-8$

4. Diegeler A, Borgermann J, Kappert U, Breuer M, Böning A, Ursulescu A, et al. Off-pump versus on-pump coronary-artery bypass grafting in elderly patients. $N$ Engl J Med. 2013;368:1189-98.

5. Lamy A, Devereaux PJ, Prabhakaran D, Taggart DP, Hu S, Straka Z, et al. Fiveyear outcomes after off-pump or on-pump coronary-artery bypass grafting. $N$ Engl J Med. 2016;375:2359-68.

6. Shroyer AL, Hattler B, Wagner TH, Collins JF, Baltz JH, Quin JA, et al. Five-year outcomes after on-pump and off-pump coronary-artery bypass. $N$ Engl J Med. 2017;377:623-32.

7. Taggart DP, Gaudino MF, Gerry S, Gray A, Lees B, Sajja LR, et al. Ten-year outcomes after off-pump versus on-pump coronary artery bypass grafting: insights from the Arterial Revascularization Trial. J Thorac Cardiovasc Surg. 2021;162:591-9.e8

8. Taggart DP, Benedetto U, Gerry S, Altman DG, Gray AM, Lees B, et al. Bilateral versus single internal-thoracic-artery grafts at 10 years. N Engl J Med. 2019;380: 437-46.

9. Chikwe J, Lee T, Itagaki S, Adams DH, Egorova NN. Long-term outcomes after off-pump versus on-pump coronary artery bypass grafting by experienced surgeons. J Am Coll Cardiol. 2018;72:1478-86.

10. Kim HJ, Kim JB, Jung SH, Choo SJ, Lee JW, Chung CH. Coronary artery bypass grafting in patients with severe chronic kidney disease: a propensity scoreweighted analysis on the impact of on-pump versus off-pump strategies. Eur J Cardiothorac Surg. 2017;52:937-44. 